\title{
hybrid Design based research for Agile Software development (hDAS) in ISD contexts: a discovery from studying how to design MUVEs for VET
}

\section{Todd Cochrane}

Digital Technologies, School of Media Arts and Digital Technolgy, Nelson Marlborough Institute of Technology, New Zealand. ${ }^{1}$

\begin{abstract}
In this discussion a class of instructional design (ISD) processes is posited, that intrinsically trend towards increasing complexity in their design, in order to meet newly formed theoretic perspectives. hDAS is introduced, that addresses an on-going increase in complexity of ISD, through a paradigmatic change, in which the outcome of the design is also the design process adapted to current theoretical understanding and discipline needs. The way forward, as formalized in hDAS, is tailoring of ISD through DBR and Agile software development. In this paper a context for hDAS is presented by reflection on hDAS in ISD that uses: ADDIE, Agile and explicitly tests educational theory. hDAS resolves gaps identified for each of these. By enacting hDAS a tailored ISD method is induced that meets the current theoretic and vocational understanding for the instructional situation.
\end{abstract}

Keywords: DBR; Agile; ISD; MUVE; Virtual Worlds; VET.

\footnotetext{
${ }^{1}$ Acknowledgement: This paper is based on PhD study supervised by Professor Niki Davis and Associate Professor Julie MacKay at the University of Canterbury, New Zealand.
} 


\section{Introduction}

This paper discusses a paradigmatic change in processes for instructional design to instructional design through design-based research (DBR). Study of the process of educational DBR lead to the discovery of "hybrid Design based research for Agile Software development" (hDAS). In detail, the design of Multi-User Virtual Environments for vocational education and training (VET) was studied through enactment of an educational design based research (DBR) (Plomp \& Nieveen, 2007) process to create Multi-User Virtual Environments (MUVEs), i.e. Virtual World (VW) based learning and teaching environments, for vocational contexts: temporary traffic management and ship's bridge communication. "hybrid Design based research for Agile Software development" (hDAS) was discovered, that induces fit-for-purpose instructional design (ISD) process.

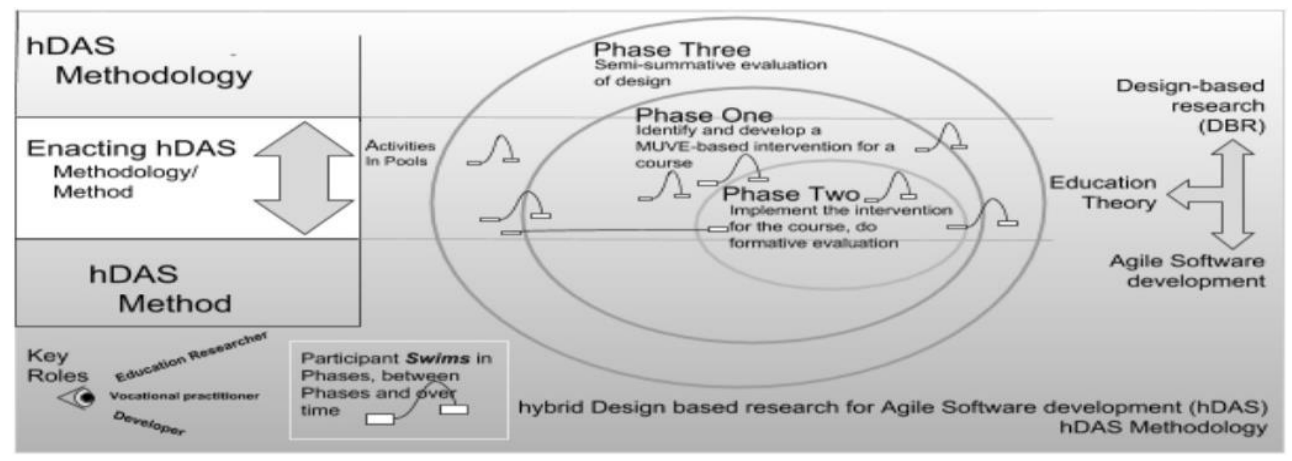

Figure 1. The relationships of key components of hybrid design based research for

Agile software development ( $h D A S)$ methodology

The purpose of the hDAS methodology is to produce a MUVE-based intervention for a vocational context, and in the process, test educational theory in the effective design of MUVEs as interventions in VET. The hDAS methodology deploys professionals from at least three disciplines to develop a MUVE: software engineering; education and the selected vocational discipline. Figure 1. depicts the relationships of key components of hDAS methodology. hDAS methodology in phases determines the tailored hDAS method. Enacting the hDAS method then leads to discoveries for and from method and methodology, which leads to further tailoring of the method. hDAS methodology is enacted in three phases. Phase two is depicted at center stage because the goal is to implement an intervention using the MUVE for VET. Phase three builds on the other two phases with ongoing feedback and evaluation of design in research practices. Phase one is depicted between Phase three and Phase two to represent the origins of design and development between research design evaluation and running an intervention. For the hDAS methodology participants take roles from three disciplines; education, software engineering and the selected vocation. The terminology used in hDAS is mainly that of the disciplines of education and software engineering (see Table 1.0). Therefore, at least three participants are required: an educational 
researcher, a vocational practitioner and a software developer. Participants from the vocation include an instructor, who is expert in the vocation, and students of the vocation. Development roles are further divided into software development, graphic design and technical support. Participants take part in enacting hDAS according to their role, which determines the phases they participate in. That participation is identified as a swim during enactment of a phase.

Table 1. Key hDAS roles by discipline and phase.

\begin{tabular}{|c|c|c|c|}
\hline Role & Discipline & Brief description & Phase/s \\
\hline Developer & $\begin{array}{l}\text { Software engineering, } \\
\text { Computer graphics } \\
\text { design Information } \\
\text { technology support }\end{array}$ & $\begin{array}{l}\text { A developer designs and develops } \\
\text { digital artefacts i.e. a software } \\
\text { developer, or a graphics designer. A } \\
\text { technician provides technical support } \\
\text { for the development and during the run } \\
\text { of an intervention }\end{array}$ & $\begin{array}{l}\text { One and } \\
\text { Two }\end{array}$ \\
\hline $\begin{array}{l}\text { Educational } \\
\text { researcher }\end{array}$ & Education & $\begin{array}{l}\text { The educational researcher directs MUVE } \\
\text { development according to the research } \\
\text { design, collects and analyses the data in } \\
\text { research on theory in practice. At least one } \\
\text { educational researcher is required. }\end{array}$ & $\begin{array}{c}\text { One and } \\
\text { Three }\end{array}$ \\
\hline $\begin{array}{l}\text { Vocational } \\
\text { practitioner }\end{array}$ & Selected vocation & $\begin{array}{l}\text { A vocational practitioner is an expert } \\
\text { member of the selected vocation. A } \\
\text { teaching practitioner is preferred. }\end{array}$ & $\begin{array}{c}\text { One and } \\
\text { Two }\end{array}$ \\
\hline $\begin{array}{l}\text { Vocational } \\
\text { trainees }\end{array}$ & & $\begin{array}{l}\text { Students of the vocation participate as } \\
\text { trainees in practices of the vocation. }\end{array}$ & \\
\hline
\end{tabular}

Throughout the enactment of the methodology, DBR hybridization with Agile software development tailors the Agile method, because the design research pragmatically determines new and required objects, including those that provide guidance of the design for the vocation. For example, the vocation has specific, legitimate practices that are used for the initial tailoring of the Agile method mandatory for the design and development to proceed. As more is learned about the professional practice, the Agile method is refined (re-tailored or re-factored in software engineering terms) to implement an improved understanding of the requirements, while still conforming with the Agile principles. Each time the hDAS Agile tailored method is enacted, all documentation and tracking of the Agile software development method as it is enacted is archived by the software developer for use in phase three.

hDAS addresses an on-going increase in complexity of ISD, through a paradigmatic change, in which the outcome of the design is also the design process adapted to current theoretical understanding and discipline needs. In this paper ISD through hDAS is placed in context by reflection on hDAS with three exemplars from the following categories of ISD. As identified 
by Soto (2013) the most prevalent approach to IDS for MUVEs was ADDIE (Allen, 2006); a second category applies Agile in ISD and a third explicitly selects educational theory to use in ISD. hDAS resolves gaps identified for each of these categories; by enacting hDAS an ISD method is induced that meets the current theoretic and vocational understanding in the instructional situation.

\section{Background - ADDIE and Agile method tailoring}

Soto (2013) identifies ADDIE as the most prevalent approach to ISD in MUVE based instruction. Allen (2006) describes Analysis, Design, Development, Implementation and Evaluation (ADDIE) as an ISD model developed post-World War II in the 1940s, applied in highly specified jobs for "systematic training within a military context of learning highly specified job tasks by a continuous cadre of homogenous learners" (p. 432). That is, ADDIE models mainly take a behavioral learning theory approach that meets training in procedural tasks. As noted by Allen (2006) ADDIE models can be classified as first, second, third and four generation models. The second-generation models adopted systems theory to control and manage more complex instructional development processes. The third-generation models were developed for flexibility needed outside of the military and phases were considered interactive processes that could be entered into at any point. While these were still mainly driven by behavioral learning theory, cognitive theory was applied in their process, e.g. in simulations to gather "cognitive expertise in decision making (Driscoll, 2005)" in Allen (2006, p. 431). Fourth generation models use developments in artificial intelligence to handle the complexity of the ADDIE system "with a continuous evaluation and troubleshooting process" Allen (2006) citing (Gagne et al. 2005), (pp. 432 to 433). The new "complexity of the ADDIE system" (p. 432) comes from "advancements in understanding how humans learn and educational technology ... provided major changes in many of the system variables" (p. 432). The ongoing focus on evaluation appears to be related to an emerging understanding that ADDIE required integration or adjustment to base it on new theory.

In order to meet newly formed theoretic perspectives processes like ADDIE, are of the class of ISD processes that intrinsically trend towards increasing complexity in their design. The way forward is to take a paradigmatic shift towards formalized tailoring of ISD through DBR and Agile software development perspectives. The Agile Manifesto (Beck et al., 2001) is a declaration of the fundamental behavior that identifies an Agile software developer, by asserting practices valued by the practitioner. In an educational context Agile software development reflects conformance with the Agile manifesto. In this study tailoring for an educational design context was through method engineering (Esfahani \& Yu, 2010). The Agile method is integrated into a DBR methodology. In one sense, the contingency factors that determine a tailored Agile method were determined through the DBR methodology in a 
bottom up manner. In another sense the over-arching DBR methodology drives the Agile development in a top down manner. Hence, the observation by Easterday et al. (2014) that DBR is designed for each study, and each DBR method appears to use a different process, is like Agile method tailoring. Although an overarching DBR process can be summarized as in Plomp and Neiveen (2007), ISD emerges from DBR processes discovered during design for the given research study, in a manner that is equivalent to One Method Per Project described by Cockburn (1999) in which an Agile method is tailored for the project. DBR lead Agile method tailoring through hybrid DBR Agile software development revealed suited ISD.

\section{3. hDAS in ISD contexts}

To consider the context of ISD using hDAS, three categories of ISD are discussed for the design of MUVE based interventions in VET.

\subsection{Category 1 ISD - uses ADDIE}

Wang and Hsu (2009) present an example of an ISD that uses the ADDIE model for the design of MUVE-like instructional environments. Wang and Hsu then describe ADDIE as it was applied in the design. Analysis was undertaken to determine the requirements for the learning context. In this case, the instructor conducted an online survey to determine students' backgrounds and motivations. Design was the major task; the instructor created a list of tasks and made them into instructions for the students. Development was undertaken by the instructor, who worked on the navigation in the VW, took images for the webpage and made sure the objects of interest were in the VW. During implementation of the intervention, student instruction was assisted through a learning management system on a webpage outside the MUVE. According to Wang and Hsu (2009) evaluation was facilitated by inviting a faculty member to observe the MUVE.

In this case, ADDIE constituted a systematic method that helped the instructor design learning tasks that would take place in a MUVE and that would ensure the MUVE's function as a tool assisting teaching and learning, (p. 81). The use of ADDIE described by Wang and Hsu (2009) differed from hDAS in several ways: (1) it did not undertake any investigation into educational theory; (2) ADDIE did not inform the design process; (3) it was an ad-hoc, checklist approach to designing and developing an instructional situation; (4) it did not inculcate theory into ADDIE; (5) although ADDIE expressed behavioral learning theory, opportunities for constructivist learning were not pursued and (6) did not inculcate constructivist-guided activities during the instructional design. This comparison shows that the hDAS focuses on research into how to design MUVEs for VET whereas using ADDIE as a checklist for instructional design of the MUVEs would not. 


\subsection{Category 2 ISD - uses Agile}

In the second category of ISD, the application of Agile in an instructional design process is presented in two studies. Dass and Cid (2018) describe the application of Agile in the design of a medical simulation, and Cooney and Little (2015) describe how Agile was used to overcome issues with ADDIE in a large project. Both papers compare ADDIE with Agile in the context of implementing instructional design. Cooney and Little's (2015) study is representative of the application of Agile in instructional design. They describe using Agile principles in the context of an ISD project that was not making good progress. They implemented a Kanban-style Agile process (Raju \& Krishnegowda, 2013) that avoided issues with the first generation ADDIE, in which they had difficulty with the formal turnover of work from one step to the next in the sequence, and the Agile process removed the complex communication that would arise in later iterative versions of ADDIE. Moving to Agile as a process for ISD, the project was delivered by the small team. They note that Agile has been used in various forms for ISD and conclude that, "What is missing from all of these is an emphasis on the Agile values and principles fundamental to Agile ISD's success, and a meaningful commitment to incorporating scrum methods" (p. 11).

Comparing the Agile-based ISD process as applied by Cooney and Little (2015) with the hDAS reveals several differences. Cooney and Little describe the use of the Agile principles to ensure they kept on track during the ISD process, while in hDAS, the Agile principles become a foundation for directing the Agile software development method in the process. The hDAS does not explicitly use Agile to manipulate design; it is the process through which design is enabled, and hence, hDAS is guided by the Agile principles. The Agile-based ISD process, as applied by Cooney and Little (2015), does not consider educational theory and is not informed by research that tailors an Agile software development method to suit the changing situation as the educational design is better understood. These features are the hallmark of the hDAS methodology.

\subsection{Category 3 ISD - explicitly tests educational theory}

The final category discussed are ISD models that explicitly select educational theory to use in the ISD process. Davies, et al. (2018) present an ISD model to address the gap between the development of simulation systems and the applied use of educational theory. They apply a five-stage educational framework called the ADELIS model to ensure that both learning, and assessment are valid in the simulation intervention. The focus is on developing an authentic learning activity. According to Davies, et al. (2018), the framework provides opportunities for measuring the intervention, the learning and behaviors in the immediate situational context, and the impact of the exercise from the view of educators and participants. Design using the ADELIS framework starts with the selection of a part of a course or curriculum that is suited to simulation and considers the simulation across course units and 
interconnections between simulations. The first process is followed by a constructive alignment process where the intervention through the simulation design is aligned to develop Learning Outcomes (LO) using an educational taxonomical vocabulary, based on the LOs assessment is derived based on appropriate theories that suit the learning process from that simulation. The third step develops content based on the LOs using educational theory that underpins and addresses Los and assessment criteria, and the required psychological and technical quality (fidelity) that encourages participant buy in is determined. In the fourth step aims methods of associated research, with validated and reliable evaluation tools are determined by the designer. In the fifth step a protocol is established for the simulation developer that identifies and assures educational fidelity and authenticity in the simulation.

The ADELIS Model is a framework, from which to induce a process for the design of simulations for interventions, that are going to be developed by a developer who is a third party to the design process. Educational research is part of the framework, but there is a sense that the research is not intrinsic to the overall process. hDAS is a research methodology by design, hence enacting the hDAS methodology intrinsically becomes design-based research. hDAS prescribes a Swim technique for analysis that generates semi-summative evaluations of the process, while at the same time reporting of the effect of theory in the context of the enacted hDAS process, that includes design development and running of interventions in with the MUVE is live educational contexts. ADELIS presents a framework that does not include refinement of its use in practice in the direct manner that is intrinsic to hDAS. hDAS goes beyond ADELIS in the aspect of development of the MUVE, by inducing and tailoring an Agile software development method that suits the design of the MUVE based intervention through practice and as the needs of the intervention are discovered.

\section{Conclusions}

hDAS provides a solution that is supported by Cockburn (1999) "one method per project" assertion and proposal for real-time adjustments to methods for software development. By hybridizing with DBR to maintain the fitness for educational purposes over time, ISD induced through hDAS avoids the trap, in which although the software development process is Agile, the methodology was tailored to fit an early understanding of the requisite design, however as the focus of the design is refined and better understood the original methodology no longer suits the project. As discovered in this study on how to design MUVEs for VET, hDAS paradigmatically changes the approach to ISD. hDAS tests theory in practice to produce useful artefacts, and design research becomes a foundation through which to develop an understanding of theory in practice while producing vocationally suited MUVEs that are VWs of the vocation. That means that there is no longer the stress where an ISD model and/or process must be adjusted to fit new education theory; instead the design process reflects the research and development contexts. 


\section{References}

Allen, W. C. (2006). Overview and Evolution of the ADDIE Training System. Advances in Developing Human Resources, 8(4), 430-441. https://doi.org/10.1177/1523422306292942.

Beck, K., Beedle, M., van Bennekum, A., Cockburn, A., Cunningham, W., Fowler, M., Grenning, J., Highsmith, J., Hunt, A., Jeffries, R., Kern, J., Marick, B., Martin, R. C., Mellor, S., Schwaber, K., Sutherland, J. \& Thomas, D. (2001). Manifesto for Agile Software Development. Retrieved August 10, 2015, from http://agilemanifesto.org/

Campanelli, A. S., \& Parreiras, F. S. (2015). Agile methods tailoring :A systematic literature review. Journal of Systems and Software, 110, 85-100. https://doi.org/10.1016/j.jss.2015.08.035

Cockburn, A. (1999). Methodology per project (Humans and Technology Technical Report). Retrieved from http://alistair.cockburn.us/Methodology+per+project

Cooney, L., \& Little, A. (2015). Implementation of Agile Methods within Instructional Systems Design: A Case Study, 12.

Dass, D. S., \& Cid, V. (2018a). An Agile ISD Process to Develop a Medical Simulation, 10.

Davies, D. A., Abu, R. A., \& Leigh, D. E. (2018). Advancing Capability: Designing Authentic Simulation-based Teaching, Learning and Assessment. In Interservice/Industry Training, Simulation, and Education Conference (I//TSEC) 2018 (p. 13). Dass, D. S., \& Cid, V. (2018a). An Agile ISD Process to Develop a Medical Simulation, 10.

Easterday, M., Lewis, D. R., \& Gerber, E. (2014). Design-based research process: Problems, phases, and applications. In Proc. Of International Conference of Learning Sciences (Vol. 14).

Esfahani, H., \& Yu, E. (2010). A repository of Agile Method Fragments. In New modeling Concepts for Today's Software Processes (pp. 162-174). Paderborn, Germany: SpringerVerlag Berlin Heidelberg, Germany.

Plomp, Tjeerd, \& Nieveen, N. (Eds.). (2007). An introduction to Educational Design Research (3rd print, March 2010). Enschede, the Netherlands: SLO. Retrieved from http://www.slo.nl/downloads/2009/Introduction_20to_20education_20design_20researc h.pdf/download

Raju, H. K., \& Krishnegowda, Y. T. (2013). Kanban pull and flow - a transparent workflow for improved quality and productivity in software development. Stevenage: The Institution of Engineering \& Technology. Retrieved from http://search.proquest.com.ezproxy.canterbury.ac.nz/docview/1776432198?accountid= 14499

Soto, V. (2013). Which Instructional Design Models are Educators Using to Design Virtual World Instruction? JOLT, Vol. 9(No. 3). Retrieved from http://jolt.merlot.org/vol9no3/soto_0913.htm

Wang, S.-W., \& Hsu, H.-Y. (2009, November). Using the ADDIE Model to Design Second Life Activities for Online Learners. TechTrends, 53(6), 76-81. 